\title{
Algebraic robust control of a closed circuit heating-cooling system with a heat exchanger and internal loop delays
}

\author{
Libor Pekař*, Roman Prokop
}

Department of Automation and Control Engineering, Faculty of Applied Informatics, Tomas Bata University in Zlín, Nad Stráněmi 4511 , 76005 Zlín, Czech Republic

\section{HIGHLIGHTS}

- The anisochronic model of a circuit heat plant with the air-water heat exchanger covering internal delays of a high accuracy was developed.

- Algebraic controller design over a special ring of quasipolynomial meromorphic functions is used to design controller structure.

- Time delays are non-approximated in the design procedure, which preserves the substantial information.

- Controller parameters are set to keep robustness conditions due to model uncertainties and environmental disturbances, and such that they reduce overshoots and consummated energy.

- The infinite-dimensional controller results are compared to the use of a finite-dimensional simplified controller.

\section{ABSTRACT}

This study demonstrates the use of a simple algebraic controller design for a cooling-heating plant with a through-flow airwater heat exchanger that evinces long internal delays with respect to the robustness to plant model uncertainties and variable ambient temperature conditions during the season. The advantage of the proposed design method consists in that the delays are not approximated but fully considered. Moreover, the reduction of sensitivity to model parameters' variations yields the better applicability regardless modeling errors or environmental fluctuations. The infinite-dimensional mathematical model of the plant has been obtained by using anisochronic modeling principles. The key tool for the design is the ring special of quasipolynomial meromorphic functions $\left(R_{Q M}\right)$. The Two-Feedback-Controllers (TFC) rather than the simple negative control feedback loop is utilized, which enables to solve the reference tracking and disturbance rejection independently and more efficiently. The eventual controller is then tuned such that robust stability and robust performance requirements are fulfilled. The tuning procedure is supported by a performance optimization idea. Since the originally obtained controller is of the infinite-dimensional nature, a possible way how to substitute it by a simplified finitedimensional one is proposed for engineering practice. The functionality of both the controllers is compared and verified by simulations as well as by real measurements which prove a very good performance.

Keywords

Heat exchanger, algebraic control design, time-delay systems, robustness, Two-Feedback-Controllers (TFC)

\section{Introduction}

Internal or state delay is the phenomenon that generically appears in many industrial, economical, biological and other systems and processes [1]-[3]. It is a challenging task to deal with this effect when investigating control laws since delays significantly deteriorate system dynamic and stability properties due to the infinitedimensional character of the controlled system [3], [4]. Although many various approaches have been derived during recent decades [1]-[3], [5], mainly in the state-space formulation, they are mostly hard to be practically implemented due to their mathematical complexity, even by considering linear time-invariant time delay systems
(LTI TDSs); for instance, robust optimal $H_{\infty}$ control design [6] yielding complex values controller parameters.

An effective and engineeringly affable way how to deal with control and stabilization tasks for TDSs may consist in the introduction of the fractional representation approach [7] in the input-output space via the Laplace transform. It can be extended from habitual rational transfer functions for finite-dimensional systems to TDSs in various algebras [8]. Within our research framework, we have been concentrated on the fractional representation over the ring of special quasipolynomial meromorphic functions $\left(R_{Q M}\right)$, originally defined in [9] and revised and extended in [10]. This algebraic structure stands between $H_{\infty}$ and BIBO (Bounded-Input Bounded-Output) stable fractions. It does

${ }^{\star}$ Corresponding author: Tel.: +420576035261

Email address: pekar@fai.utb.cz 
not require any rational approximation of exponential terms; hence, the information about delay included in the model can be fully utilized. Moreover, it is usable to even neutral, distributed or non-commensurate delays, and is based on the knowledge that that the z-transform and the Laplace transform operators are not independent from the functional point of view. Stabilization and control design problems such as reference tracking and disturbance rejection are sufficiently simple to be solved by using $R_{Q M}$, usually based on the dealing with the Bézout identity [11].

Heat exchangers (HXs) are requisite in a wide range of industrial processes, particularly in the energetic, metallurgical, chemical ones and processing of polymers [12]. In order to enhance the overall control response, improve their operation or reduce energy consumption, various advanced control strategies for such complex systems have been developed and implemented. Optimal or optimization procedures constitute the way how to cope with the problem as a matter of course [13], [14]. Wang et al. proposed an online adaptive controller for a plant containing HXs [15]. Model predictive control (MPC) approaches perform the optimized quadratic cost function of the future reference tracking by prediction of the process output over the control horizon and the energy consumption via the control action subject to constrains. For instance, an explicit MPC design based on a piecewise affine model of a boiler-turbine unit was presented in [16]. However, the plant model can not be always perfect. Robust control strategies aim to obtain controllers, the performance of which is sufficiently insensitive to model uncertainties and disturbances. An approximate robust linearizing feedback with an observerbased uncertainty estimator has been proposed in [17]. A model-based geometric control design including robustness issues for a counter-current $\mathrm{HX}$ was published in [18]. Bakošová and Oravec [19] proposed an advanced robust MPC (RMPC) controller for three counter-current $\mathrm{HXs}$ in series. An alternative approach for the control of compact plate HXs which can be implemented without the knowledge of the heat transfer behavior and is robust against changes in the coolant supply system was proposed in [20]. Recently, methods of artificial intelligence became popular and attractive tools in modeling and control of complex systems. Artificial neural networks (ANNs) in conjunction with internal model control to perform non-adaptive and adaptive control of the air temperature leaving a single-row water-to-air n-tube $\mathrm{HX}$ was proposed in [21]. The use of ANNs may lead to better energy saving compared to habitual PID control as shown e.g. in [22]. A complex control structure with two controllers combining the ANN and the fuzzy controller was designed in [23]. The simulated annealing principle used to an efficient simultaneous synthesis method for $\mathrm{HX}$ network to provide satisfactory network designs with acceptable computational effort was suggested by [24].

Closed thermal plants, processes and networks with circulating medium and HXs are inherently systems with internal delays caused by the distributed parameters and transmission latencies in the pipelines, as was studied by many authors [21], [24], [25]. Moreover, modeling and control of networks with $\mathrm{HXs}$ is a difficult task because of their complex dynamics due to nonlinearity, distributed or time-varying parameters, etc. Pipe and fluid temperature variations due to flow were analyzed by Saman and Mahdi [26]. Zítek et al. modeled and studied the effect of latencies in HX networks by using the anisochronic principle and proposed a quasipolynomial based controller with the dominant spectrum placement [25]. Similar principles were used in [27] yet in the formulation of a state-space feedback controller. There was stated in [28] that $\mathrm{HXs}$ are represented by nonlinear delayed models; however, delay was not explicitly considered when designing a RMPC control law. A higher order finitedimensional model of the $\mathrm{HX}$ with the input-output delay was used in [22], [23] for the comparison of some control methods with the proposed ANN predictive controllers. A controller based on the combination of the ANN and MPC was designed for a class of nonlinear systems with constant input and state-feedback delays in [29]. Oravec et al. [30] presented a complex advanced RMPC of a heating-cooling networked system with a $\mathrm{HX}$ where the influence of uncertain parameters was taken into account. The resulting optimization problem with constraints was formulated in the form of linear matrix inequalities here; however, fluid transport latencies were not considered in the model despite of long pipelines. A combined feedforward and feedback control system to recover waste heat in cars was proposed by [31].

In this paper, we aim to control a circuit laboratory system with a heater and the cooling by means of an airwater $\mathrm{HX}$, assembled in the labs of authors. The appliance may represent e.g. a small-scale model of the cooling system in cars [31]. Considering control strategies applied of this laboratory appliance or its mathematical model, works of Bobál and his team have to be referred. To name just a few, different generalized MPC methods with the measurement of the delayed disturbance was, respectively, proposed in [32] and [33], and a simulation verification of the digital Smith predictor based on the polynomial approach with the minimization of the linear quadratic criterion was published in [34]. However, in the cited works, input-output delays were solely assumed without any attempt to include internal delays in the simple discrete-time linear model.

We derived a mathematical model of the laboratory appliance [35] via the anisochronic modeling principle [25]. This methodology enables to simply include all significant plant delays and latencies due to the fluid flow into the infinite-dimensional model and provides a very good closeness to the real dynamic responses. This paper is aimed at the application of principles of robust stability and robust performance to the model, both in the reign of simulations and practical verification. There is a triple reason for the use of robustness tools in our control task. As first, significant measurement and model uncertainties appear when parameterization the model. Measured output temperatures are naturally affectedd by voltage fluctuations and a limited sensor resolution yielding the quantization noise. Voltage inputs to the model are transformed to heat power or to the rotating motion of 
mechanical parts. During this, friction and hysteresis exert such that angular velocity deviations can be observed, which may cause delay variations in addition. Measured data are then processed by using the least means square method, which inherently induces model imperfections. Second, ambient temperature in the laboratory room varies during the year in the range from 18 to $28^{\circ} \mathrm{C}$. Last but not least, during the control process, manipulated input varies according to the control law, and hence, internal delays due to the fluid flow are not constant. These facts give grounds for the application of robustness tools [36].

The above introduced model-based algebraic approach in the RQM ring is utilized. The development of the $R_{Q M}$ concept and an investigation of its properties were among main authors' research tasks during recent years. We are also motivated by the fact that according to the authors' best knowledge, the algebraic fractional approach has never been used to practical control of delayed circuit heating systems and networks with HXs. The anisochronic model of the laboratory appliance [35] perfectly fits the class of systems to be suitable handled by the used algebraic structure; especially, internal delays can be addressed. Heretofore, state-space [27] and quasipolynomial approaches [25] were applied to such systems when dealing with fully (non-approximated) anisochronic models. Therefore, there is a natural endeavor to apply and verify our results on some practically-oriented problem. Control design in the introduced ring is, moreover, quite simple and engineeringly easy-to-handle, and it is based solely on algebraic operations with quasipolynomial fractions. Control law parameterization is then composed of the combination of the quasipolynomial pole placement, simulation experiments to satisfy the robustness issues and also by the optimization procedure to find a trade-off between performance quality measures.

In addition, we decided to use Two-FeedbackControllers (TFC) control system [37] instead of the habitual control feedback loop since it is then possible to decouple stabilization, reference tracking and disturbance rejection tasks within this structure.

As the model delays remain non-approximated, the eventual controller structure has an infinite-dimensional nature. Although it has been proved that controllers of this family can easily be implemented e.g. by using programmable logic controllers (PLC) [38], linear finitedimensional controllers of the proportional-integralderivative (PID) type prevail in the industrial practice [39]. Hence, a simple rationalization method is proposed to get a generalized PID controller structure, and it is benchmarked against the original control law.

\section{Theoretical background of control design in $R_{Q M}$}

The notation used in the paper is as follows: $\mathrm{C}$ and $\mathrm{R}$ denote the set of, respectively, complex and real numbers, $\mathrm{R}^{n}$ is $\mathrm{n}$-dimensional space of real-valued vectors. For $s \in \mathrm{C}, \operatorname{Re}(s)$ denotes the real part and imaginary part of $s$. Define $\mathrm{C}^{-}:=\{s \in \mathrm{C} \mid \operatorname{Re}(s)<0\}$. The symbol $\varnothing$ denotes the empty set. It holds that $(.) \in H_{\infty} \Leftrightarrow\|(\cdot)\|_{\infty}:=\sup _{\operatorname{Re}(s) \geq 0}|(\cdot)|<\infty$. For a vector or matrix $\mathbf{A}$, its transpose is denoted as $\mathbf{A}^{T}$.

\subsection{Controlled system and its description in $R_{Q M}$}

The controlled LTI TDS is initially considered in the form of the quasipolynomial transfer function as the fraction $G(s)=b(s) / a(s)$, which is the direct consequence of the use of the Laplace transform. A quasipolynomial reads

$q(s)=s^{n}+\sum_{i=0}^{n} \sum_{j=0}^{k_{i}} q_{i j} s^{i} \exp \left(-\tau_{i j} s\right)$

where $\quad q_{i j} \in \mathrm{R}, \quad \tau_{i 0}=0, \quad \mathbf{T}=\left[\tau_{01}, \tau_{02}, \ldots, \tau_{n k_{n}}\right] \in \mathrm{R}^{L}>0$ are general delays and $L=\sum_{i=0}^{n} k_{i}, s$ stands for the Laplace transform variable. Let us denote the set of quasipolynomials as $r_{Q}[s]$.

The $R_{Q M}$ ring is defined as follows [10]: $T(s)=n(s) / d(s) \in R_{Q M}, \quad$ where $\quad n(s), d(s) \in r_{Q}[s]$, $n(s)=\tilde{n}(s) \exp (-\tau s), \quad \tau \geq 0 ; T(s) \in H_{\infty}$ and it is formally stable.

Formal stability means that $\Sigma_{a}:=\left\{s \in \mathrm{C}^{-}: d_{a}(s)=0\right\}=\varnothing \quad$ where $d_{a}(s)=1+\sum_{j=1}^{k_{n}} d_{n j} \exp \left(-\tau_{n j} s\right) \quad$ is the associated exponential polynomial. Note that $T(s)$ is always proper since the inclusion in $H_{\infty}$ implies the general definition of the properness [40]. Then the controlled process transfer function can be written in the form

$G(s)=B(s) / A(s)$

where $A(s), B(s) \in R_{Q M}$ are coprime in the sense that they do not have any common non-invertible element from $R_{Q M}$.

\subsection{Essentials of controller design in RQM for TFC}

The TFC structure used to control design is depicted in Fig. 1 in which $u_{0}(t), y(t), r(t), e(t)$ denote the manipulated input, the process output, the reference signal and the control error, respectively. The controlled process input affected by the disturbance $d(t)$ is denoted as $u(t)$.

The inner and outer controllers, respectively, are represented by transfer functions $G_{Q}(s)=Q(s) / P(s)$, $G_{C}(s)=C(s) / P(s), \quad C(s), Q(s), P(s) \in R_{Q M}$, and let the Laplace forms of external inputs - the reference signal and the load disturbance - be of the forms $R(s)=\cdot / F_{R}(s)$, $D(s)=\cdot / F_{D}(s)$, respectively, where $F_{R}(s), F_{D}(s) \in R_{Q M}$. The feedback system is stabilized by the solution of the Bézout identity

$$
A(s) P(s)+B(s) V(s)=1
$$

where $V(s):=C(s)+Q(s)$. 


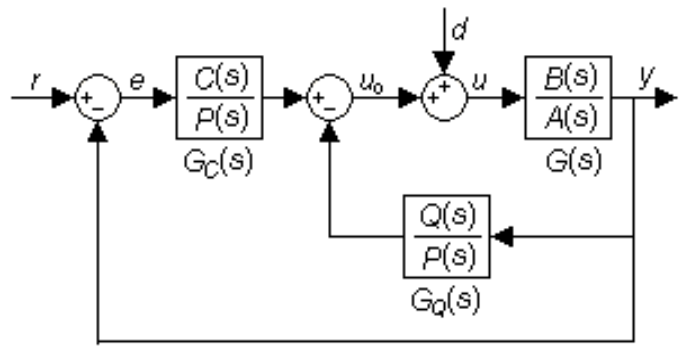

Fig. 1. TFC control structure.

The complete solutions set can be obtained by the parameterization of a particular solution pair $P_{0}(s), V_{0}(s)$ as

$P(s)=P_{0}(s) \pm B(s) Z(s) \neq 0, V(s)=V_{0}(s) \mp A(s) Z(s)$

for an arbitrary $Z(s) \in R_{Q M}$. Some other control performance requirements can be satisfied via parameterization (4). Namely, load disturbance rejection and reference tracking constitute the most natural demands in practice.

The undesirable input $d(t)$ is asymptotically rejected if

$(B(s) P(s)) / F_{D}(s) \in R_{Q M}$

and the signal $r(t)$ is asymptotically tracked if

$(A(s) P(s)+B(s) Q(s)) / F_{R}(s) \in R_{Q M}$

Details about a possible solution of (1) and the divisibility in $R_{Q M}$ can be found in [10]. In order to satisfy (5) and (6) simultaneously, $V(s)$ has to be decomposed as follows: Let $v_{N}(s) \in r_{Q}[s]$ be the numerator of $V(s)$ with realvalued coefficients $v_{N, i j}$.

Then the numerator quasipolynomial of $Q(s)$ reads

$q_{N}(s)=\left(1-\gamma_{n 0}\right) s^{n}+\sum_{i=0}^{n} \sum_{j=0}^{k_{i}}\left(1-\gamma_{i j}\right) v_{N, i j} s^{i} \exp \left(-\tau_{i j} s\right)$

where $\quad \gamma_{i j} \in[0,1], i=0,1, \ldots n, j=0,1 \ldots k_{i} \quad$ are weight parameters, the appropriate values of which are to be set such that $(B(s) Q(s)) / F_{R}(s) \in R_{Q M}$.

\subsection{Robustness issues}

Let the family of transfer functions be formulated in the form of unstructured multiplicative uncertainties as $G(s)=\left(1+\Delta(s) W_{M}(s)\right) G_{0}(s)$ where $G_{0}(s)$ expresses the nominal (unperturbed) plant transfer function with the same number of unstable poles as $G(s), W_{M}(s)$ is a fixed stable weight function expressing the uncertainty frequency distribution and $\|\Delta(s)\|_{\infty} \leq 1$ is stable. Moreover, $G(s)$ and $G_{0}(s)$ have the same number of unstable poles. It holds that

$\left|\frac{G(\mathrm{j} \omega)}{G_{0}(\mathrm{j} \omega)}-1\right| \leq \mid W_{M}(\mathrm{j} \omega), \forall \omega \geq 0$
Robust stability expresses the ability of the control system to remain exponentially stable for all $G(s)$. By using principles introduced e.g. in [36], the following robust stability condition for the TFC system with a LTI TDS can be derived

$\|R S(\mathrm{j} \omega)\|_{\infty}:=\left\|W_{M}(\mathrm{j} \omega) T_{0}(\mathrm{j} \omega)\left(1+\frac{G_{Q}(\mathrm{j} \omega)}{G_{C}(\mathrm{j} \omega)}\right)\right\|_{\infty}<1$

where $T_{0}(s)$ agrees with the nominal transfer function through which $y(t)$ is related to $r(t)$.

Robust performance is met if all transfer functions $S(s)$ from $r(t)$ to $e(t)$ (so-called sensitivity functions) within the family $G(s)$ have their gain smaller than the prescribed sensitivity weight function $W_{P}(s)$ for the whole frequency range, and simultaneously, condition (9) is satisfied. After some calculations, one can obtain the following robust performance condition

$\left\|R S(\mathrm{j} \omega)|+| W_{P}(\mathrm{j} \omega)\left(S_{0}(\mathrm{j} \omega)+R S(\mathrm{j} \omega)\right)\right\|_{\infty}<1$

In this paper, we apply (9) and (10) to determine robustness parameters of the eventual controllers derived by using (3)-(7) for the uncertain heating-cooling process with a $\mathrm{HX}$ introduced in the next section.

\section{HX network and its model}

The description and mathematical model of the controlled process (Figs. 2 and 3 ) with a HX are introduced hereinafter. The plant has been used for experimental verification of the proposed robust control strategy.

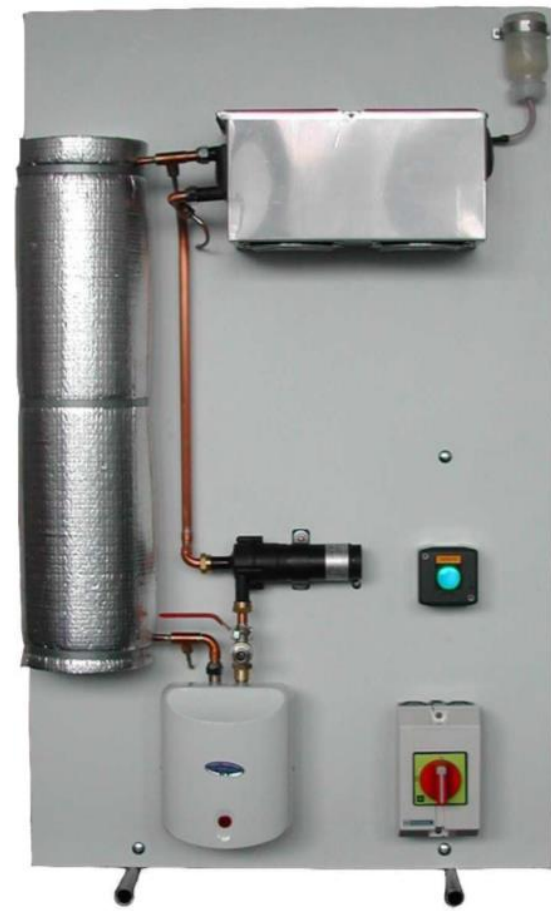

Fig. 2. The controlled process photo appearance. 


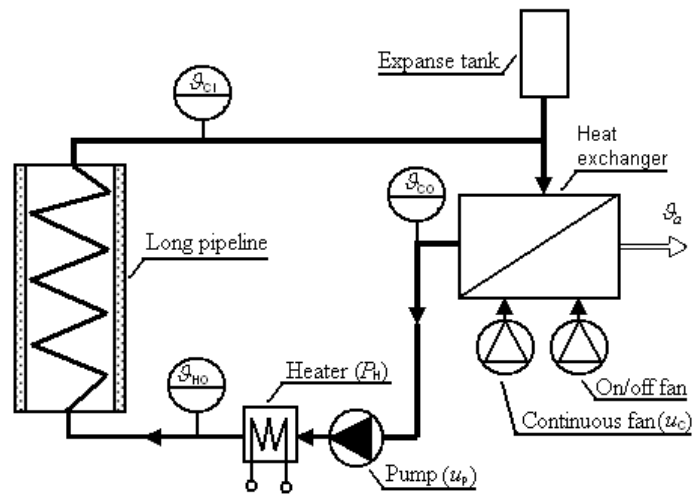

Fig. 3. A scheme of the controlled laboratory system with a HX.

\subsection{Controlled process description}

The appliance can be described as follows: A continuously controllable magnetic drive centrifugal pump CM30P7-1 with the input voltage range of $u_{\mathrm{P}}(t) \in[0,10] \mathrm{V}$ transports the fluid through a flow heater of the maximum heat power $P_{\mathrm{H}}(t)=750 \mathrm{~W}$ controlled by TTL binary signal. The outlet water temperature value from the heater is measured as $\vartheta_{\mathrm{HO}}(t)$ by means of a platinum resistance thermometer Pt1000 by Regmet [41] with 0-10V output range for the temperature range from 0 to $100{ }^{\circ} \mathrm{C}$. Hot water is then transported through a 15 meters long insulated coiled copper pipeline, which is the most influential originator of internal delays in the system. The most significant fluid temperature decline is caused by a plate-fin air-water HX connected to the pipeline. The effect of heat consumption is supported by two fans; one of them is continuously controllable by the input voltage within the range $u_{\mathrm{c}}(t) \in[0,10] \mathrm{V}$, the second one is on/off and used in emergency. Inlet water temperature is measured as $\vartheta_{\mathrm{Cl}}(t)$ and the outlet one gives the value of $\vartheta_{\mathrm{CO}}(t)$ by the same thermometer type as introduced above. The expansion effect of the water is compensated by an expansion tank situated at the top of the model. The appliance is also equipped with an inlet/outlet valve placed below the pump. The laboratory model includes a microcontroller unit that communicates with a PC equipped with a data acquisition card via serial bus RS232. All tasks relating to the monitoring and control of the plant are served by software running in the Matlab ${ }^{\circledR}$ environment with Real-Time ${ }^{\mathrm{TM}}$ toolbox.

\subsection{Controlled process modeling}

The plant modeling is based on the anisochronic principle [25] that includes all the significant delays and latencies in the model caused by the heat transferring from a source through a piping system by using the heat transferring media (water) into a heat-consuming part. Each functional part of the appliance is modeled in the form of ordinary differential equations by means of heat balances and some parts are modeled in the parlance of algebraic equations expressing static relations of particular quantities. These submodels are then linked via their common physical quantities which are delayed due to water flow.
Particular submodels of the heater, the insulated coiled pipeline and the $\mathrm{HX}$ are, respectively, the following:

$$
\begin{aligned}
c M_{\mathrm{H}} \frac{\mathrm{d} \vartheta_{\mathrm{HO}}(t)}{\mathrm{d} t}= & P_{\mathrm{H}}\left(t-0.5 \tau_{\mathrm{H}}\right)+c \dot{m}(t)\left(\vartheta_{\mathrm{HI}}\left(t-\tau_{\mathrm{H}}\right)-\vartheta_{\mathrm{HO}}(t)\right) \\
& -k_{\mathrm{H}}(t)\left(\frac{\vartheta_{\mathrm{HO}}(t)+\vartheta_{\mathrm{HI}}\left(t-\tau_{\mathrm{H}}\right)}{2}-\vartheta_{\mathrm{a}}\right) \\
c M_{\mathrm{P}} \frac{\mathrm{d} \vartheta_{\mathrm{Cl}}(t)}{\mathrm{d} t} & =c \dot{m}(t)\left(\vartheta_{\mathrm{HO}}\left(t-\tau_{\mathrm{HC}}\right)-\vartheta_{\mathrm{Cl}}(t)\right) \\
& -k_{\mathrm{P}}\left(\frac{\vartheta_{\mathrm{Cl}}(t)+\vartheta_{\mathrm{HO}}\left(t-\tau_{\mathrm{HC}}\right)}{2}-\vartheta_{a}\right) \\
c M_{\mathrm{C}} \frac{\mathrm{d} \vartheta_{\mathrm{CO}}(t)}{\mathrm{d} t}= & c \dot{m}(t)\left(\vartheta_{\mathrm{Cl}}\left(t-\tau_{\mathrm{C}}\right)-\vartheta_{\mathrm{CO}}(t)\right) \\
& -k_{\mathrm{C}}(t)\left(\frac{\vartheta_{\mathrm{CO}}(t)+\vartheta_{\mathrm{Cl}}\left(t-\tau_{\mathrm{C}}\right)}{2}-\vartheta_{\mathrm{a}}\right)
\end{aligned}
$$

where $M_{\mathrm{H}}, M_{\mathrm{P}}$ and $M_{\mathrm{C}}$ are, respectively, water masses inside the heater, the pipeline and the $\mathrm{HX}$ (cooler), $k_{\mathrm{H}}(t)$, $k_{\mathrm{P}}, k_{\mathrm{C}}(t)$ stand for analogous overall heat transmission coefficients, $\dot{m}(t)$ expresses the water mass flow, $c$ is the specific water heat capacity, $\vartheta_{a}$ means ambient temperature, and $\tau_{H}, \tau_{H C}, \tau_{C}$ express durations of water flow through the heater, that of between the heater and the $\mathrm{HX}$ and through the $\mathrm{HX}$, respectively.

In the model (11), temperatures inside submodels are considered as mean values of corresponding inlet and outlet stream temperatures, which is equivalent to the uniformly distributed fluid heat power rise or decline and delay distribution along the particular part of the model Note the mass of the copper piping is neglected in (11) since it is less than used water and, moreover, the specific heat capacity of copper $c_{C u}=385 \mathrm{~J} \mathrm{~kg}^{-1} \mathrm{~K}^{-1}$ is worth less than that of water $c=4180 \mathrm{~J} \mathrm{~kg}^{-1} \mathrm{~K}^{-1}$.

Auxiliary static relations have forms [35]:

$$
\begin{aligned}
& \vartheta_{\mathrm{HI}}(t)=\vartheta_{\mathrm{CO}}\left(t-\tau_{\mathrm{CH}}\right) \\
& \dot{m}(t)=\pi_{0}\left[u_{\mathrm{P}}(t)+\pi_{1}\right]^{\pi_{2}} \\
& k_{\mathrm{H}}(t)=\frac{h_{0} P_{\mathrm{H}}^{2}(t)+h_{1} \dot{m}^{2}(t)+h_{2} P_{\mathrm{H}}(t) \dot{m}(t)+h_{3}}{h_{4} P_{\mathrm{H}}(t)+h_{5} \dot{m}(t)} \\
& k_{\mathrm{C}}(t)=c_{2} u_{\mathrm{C}}^{2}\left(t-\tau_{\mathrm{FC}}\right)+c_{1} u_{\mathrm{C}}\left(t-\tau_{\mathrm{FC}}\right)+c_{0}
\end{aligned}
$$

where $\tau_{\mathrm{CH}}$ and $\tau_{\mathrm{FC}}$ express delay of the water flow from the HX to the heater and the cooling fan effective control latency, respectively, and $\pi_{i}, h_{j}, \quad c_{i}$ with $i=0,1,2$, $j=0,1,2,3,4,5$ are real-valued parameters.

The complete model is obtained by the combination of (11) - (15). Although the model is clearly nonlinear, static characteristics with respect to the control input $P_{\mathrm{H}}(t)$ are almost linear (Fig. 4) with corresponding particular coefficients of determination $R^{2}=0.9995,0.9993,0.9987$. Note that superscript $s$ means the steady state. Hence, linear control theory can be applied for the operating range of inputs $P_{\mathrm{H}}(t) \in[225,675] \mathrm{W}$. 


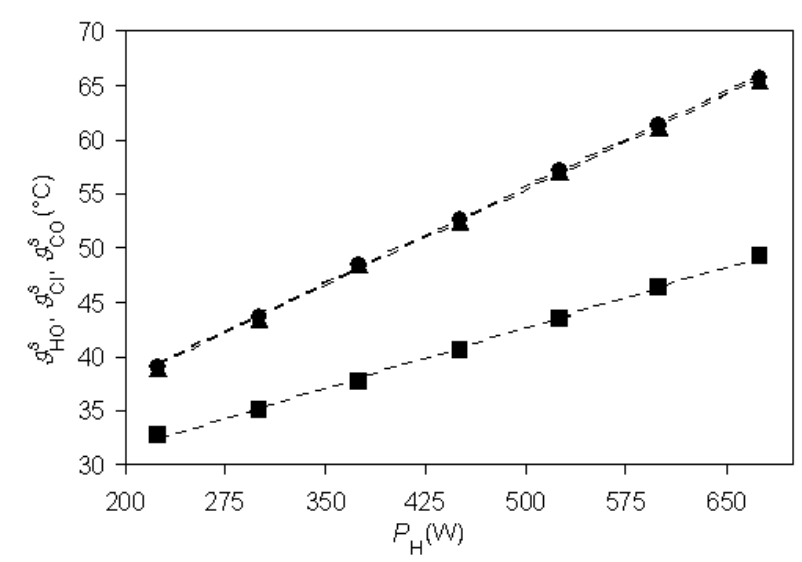

Fig. 4. Static characteristics of $\vartheta_{\mathrm{HO}}^{\mathrm{s}}$ (circles), $\vartheta_{\mathrm{Cl}}^{\mathrm{s}}$ (triangles) and $\vartheta_{\mathrm{CO}}^{\mathrm{s}}$ (squares) with respect to $P_{\mathrm{H}}$ for the operating point $u_{\mathrm{P}}=5 \mathrm{~V}, u_{\mathrm{C}}=3 \mathrm{~V}, \vartheta_{\mathrm{a}}=24^{\circ} \mathrm{C}$.

A linearized model can simply be received by using the first order term of the Taylor expansion of a particular multivariable left-hand-side function from (11) at the (steady state) operating point as

$$
\left.\frac{\mathrm{d} \vartheta .(t)}{\mathrm{d} t} \approx \frac{\mathrm{d} \vartheta \cdot(t)}{\mathrm{d} t}\right|_{\vartheta_{*}^{\mathrm{s}}, u_{i}^{\mathrm{s}}}+\left.\sum_{i=1}^{3} \frac{\partial}{\partial u_{i}(t)} \frac{\mathrm{d} \vartheta \cdot(t)}{\mathrm{d} t}\right|_{\vartheta_{*}^{\mathrm{s}}, u_{i}^{\mathrm{s}}}\left(u_{i}(t)-u_{i}^{\mathrm{s}}\right)
$$

where $u_{i}(t)$ agree with manipulated inputs $P_{\mathrm{H}}(t), u_{\mathrm{C}}(t), u_{\mathrm{P}}(t)$.

Then, by defining $\Delta u_{i}(t):=u_{i}(t)-u_{i}^{\mathrm{s}}, \Delta \vartheta(t):=\vartheta(t)-\vartheta^{\mathrm{s}}$ and by using the Laplace transform, the linearized model can be expressed as $\Delta \mathbf{y}(s)=\overline{\mathbf{G}}(s) \Delta \mathbf{u}(s)$ where

$$
\begin{aligned}
\Delta \mathbf{y}(s) & =\left[\Delta \vartheta_{\mathrm{HO}}(s), \Delta \vartheta_{\mathrm{Cl}}(s), \Delta \vartheta_{\mathrm{CO}}(s)\right]^{T} \\
\Delta \mathbf{u}(s) & =\left[\Delta u_{\mathrm{P}}(s), \Delta u_{\mathrm{C}}(s), \Delta P_{\mathrm{H}}(s)\right]^{T}
\end{aligned}
$$

stand for Laplace forms of the inputs and the outputs of the linearized model, respectively, in the vicinity of the operating point, and $\overline{\mathbf{G}}(s)$ is the $3 \times 3$ transfer function matrix.

In this paper, it is intended to control $\Delta \vartheta_{\mathrm{CO}}(t)$ by means of $\Delta P_{\mathrm{H}}(t)$, the mutual relation of which can be formulated by the transfer function

$$
G(s)=\frac{\left(b_{0}+b_{0 D} \exp \left(-\tau_{0} s\right)\right) \exp \left(-\tau_{b} s\right)}{s^{3}+a_{2} s^{2}+a_{1} s+a_{0}+a_{0 D} \exp \left(-\tau_{a} s\right)}=\frac{b(s)}{a(s)}
$$

where coefficients $b_{0}, b_{0 D}, a_{2}, a_{1}, a_{0}, a_{0 D} \in \mathrm{R}$ depend on parameters inherent in model (11)-(15) and on steady state inputs and outputs. Particular relations are omitted from this paper due to their complexity, yet can be found in [35].

\subsection{Controlled process parameters identification}

The process of the model parameter values determination has two basic steps. First, measured steady state input-output relations are used to find values of parameters on the right-hand side of (11) (except for delays); which is combined with (13)-(15), the right-hand side parameters of which are then calculated by the solution of the nonlinear least mean squares. Measured steady states for $\vartheta_{a}=24^{\circ} \mathrm{C}$ are summarized in Table 1 and corresponding eventually calculated nominal parameters' values are displayed in Table 2 . It is worth noting that the value of $k_{\mathrm{p}}$ ranges from 0.16 to $0.62 \mathrm{~J} \mathrm{~s}^{-1} \mathrm{~K}^{-1}$ within the calculations; however, it has not significant impact to system dynamics and steady-state process behavior since the value is low due to good insulation.

As second step, a dynamic response serves for the determination of masses in the model affecting dynamic indicators such as the slope of the temperature rise and descent during the dynamic response. These values are hence obtained by the matching the measured transitional part of the step response to the modeled one by means of the least means squares criterion. The particular step response has been performed (with the sampling period of $\Delta t=1 \mathrm{~s}$ and the input step change of $\Delta P_{\mathrm{H}}=150 \mathrm{~W}$ ) in the following operating point giving rise to the corresponding modeled steady-state outputs, respectively, as

$$
\begin{aligned}
& \mathbf{u}=\mathbf{u}^{\mathrm{s}}=\left[u_{\mathrm{P}}^{\mathrm{s}}, u_{\mathrm{C}}^{\mathrm{s}}, P_{\mathrm{H}}^{\mathrm{s}}\right]^{T}=[5,3,300]^{T} \\
& \mathbf{y}^{\mathrm{s}}=\left[\vartheta_{\mathrm{HO}}^{\mathrm{s}}, \vartheta_{\mathrm{Cl}}^{\mathrm{s}}, \vartheta_{\mathrm{CO}}^{\mathrm{s}}\right]^{T}=[43.6,43.4,35.1]^{T}
\end{aligned}
$$

for $\vartheta_{a}=24^{\circ} \mathrm{C}$. Hence, finite sets of input and output values relatively to the steady state have been obtained. These measured data have been then compared to the response of the linearized model in the vicinity of (19). Since it is not possible to compute delayed model step response analytically, solely simulation matching experiments have been made with the mass-value discretization step of $\Delta M=0.01 \mathrm{~kg}$ for all three masses included in model (11). As the benchmark, the sum of square errors between measured and simulated data for $t \in[1,1000] \mathrm{s}$ has been considered. This procedure yields data included in Table 3. Note that separate analyses for corresponding masses and responses can not be made due to the circuit nature of the process. For instance, $M_{H}$ can not be determined solely from the relation $\Delta P_{H} \rightarrow \Delta \vartheta_{H O}(t)$ since the corresponding transfer function includes other masses as well.

Delays can simply be deduced graphically from the step responses as particular latencies in the accordance to the analysis of water flow inside the piping. The results are given in Table 4 where the minimum and maximum values depend solely to the value of $u_{\mathrm{p}}(t)$ and the nominal values agree with the constant input of $u_{\mathrm{P}}=5 \mathrm{~V}$.

For the operating point (19), eventual nominal parameters of the transfer function (18) are presented in Table 5. 
Table 1

Measured steady-state temperature values for various input voltage and power levels and ambient temperatures.

\begin{tabular}{cccccccccccc}
\hline & & & \multicolumn{2}{c}{$\vartheta_{\mathrm{HO}}\left({ }^{\circ} \mathrm{C}\right)$} & \multicolumn{2}{c}{$\vartheta_{\mathrm{Cl}}\left({ }^{\circ} \mathrm{C}\right)$} & \multicolumn{2}{c}{$\vartheta_{\mathrm{CO}}\left({ }^{\circ} \mathrm{C}\right)$} & \multicolumn{2}{c}{$\vartheta_{\mathrm{a}}\left({ }^{\circ} \mathrm{C}\right)$} \\
\cline { 4 - 11 } & & $u_{\mathrm{C}}(\mathrm{V})$ & $P_{\mathrm{H}}(\mathrm{W})$ & $\begin{array}{c}\text { Minimum } \\
\text { value }\end{array}$ & $\begin{array}{c}\text { Maximum } \\
\text { value }\end{array}$ & $\begin{array}{c}\text { Minimum } \\
\text { value }\end{array}$ & $\begin{array}{c}\text { Maximum } \\
\text { value }\end{array}$ & $\begin{array}{c}\text { Minimum } \\
\text { value }\end{array}$ & $\begin{array}{c}\text { Maximum } \\
\text { value }\end{array}$ & $\begin{array}{c}\text { Minimum } \\
\text { value }\end{array}$ & $\begin{array}{c}\text { Maximum } \\
\text { value }\end{array}$ \\
\hline 4 & 3 & 225 & 38.1 & 41.8 & 38.0 & 41.5 & 31.3 & 35.1 & 22 & 26 \\
4 & 3 & 300 & 42.6 & 43.5 & 42.5 & 43.2 & 33.7 & 34.9 & 23 & 25 \\
4 & 3 & 375 & 47.8 & 48.1 & 47.3 & 47.9 & 36.8 & 37.1 & 23.5 & 24 \\
4 & 3 & 400 & 51.2 & 51.2 & 50.9 & 50.9 & 37.7 & 37.7 & 24 & 24 \\
5 & 1 & 300 & 45.3 & 48.1 & 46.3 & 47.9 & 38.2 & 40.0 & 21.5 & 25 \\
5 & 2 & 300 & 43.3 & 44.5 & 42.8 & 44.3 & 34.7 & 35.8 & 22.5 & 23 \\
5 & 3 & 225 & 39.4 & 40.9 & 39.3 & 40.7 & 32.9 & 34.5 & 25 & 27 \\
5 & 3 & 300 & 41.9 & 44.1 & 41.8 & 43.8 & 33.3 & 36.0 & 22.5 & 25 \\
5 & 3 & 375 & 48.5 & 49.9 & 48.4 & 49.7 & 37.7 & 40.0 & 24 & 26 \\
5 & 3 & 400 & 52.2 & 52.2 & 52.0 & 52.0 & 39.9 & 39.9 & 24 & 24 \\
5 & 3 & 450 & 52.8 & 52.8 & 52.7 & 52.7 & 40.6 & 40.6 & 24 & 24 \\
5 & 3 & 525 & 57.3 & 57.3 & 57.1 & 57.1 & 43.5 & 43.5 & 24 & 24 \\
5 & 3 & 600 & 61.3 & 61.3 & 61.1 & 61.1 & 46.4 & 46.4 & 24 & 24 \\
5 & 3 & 675 & 65.7 & 65.7 & 65.4 & 65.4 & 49.3 & 49.3 & 24 & 24 \\
5 & 4 & 300 & 39.8 & 43.1 & 39.3 & 42.8 & 30.0 & 34.5 & 20.5 & 25.5 \\
5 & 5 & 300 & 39.6 & 40.9 & 39.3 & 40.6 & 31.0 & 32.3 & 21 & 24 \\
5 & 6 & 300 & 38.6 & 40.6 & 38.4 & 40.5 & 30.2 & 32.2 & 21 & 24.5 \\
6 & 3 & 225 & 38.0 & 39.5 & 37.9 & 39.3 & 32.9 & 33.0 & 23.5 & 25.5 \\
6 & 3 & 300 & 43.3 & 43.4 & 42.8 & 43.1 & 35.2 & 35.3 & 24 & 24 \\
6 & 3 & 375 & 48.2 & 49.1 & 47.8 & 48.9 & 38.3 & 39.5 & 23 & 26.5 \\
6 & 3 & 400 & 49.9 & 49.9 & 49.8 & 49.8 & 38.2 & 38.2 & 23 & 23 \\
\hline
\end{tabular}

Table 2

Identified parameters of the model from steady-state values.

\begin{tabular}{|c|c|c|}
\hline Parameter & Unit & Nominal value \\
\hline$\pi_{0}$ & $\mathrm{~kg} \mathrm{~s}^{-1}$ & $5.077 \times 10^{-3}$ \\
\hline$\pi_{1}$ & V & 0.266 \\
\hline$\pi_{2}$ & 1 & 0.274 \\
\hline$h_{0}$ & $s J^{-1} K^{-1}$ & 8.493 \\
\hline$h_{1}$ & $\mathrm{~s} J \mathrm{~kg}^{-2} \mathrm{~K}^{-1}$ & $-1.7 \times 10^{-3}$ \\
\hline$h_{2}$ & $\mathrm{~J} \mathrm{~kg}^{-1} \mathrm{~K}^{-1}$ & -14999 \\
\hline$h_{3}$ & $\mathrm{~J} \mathrm{~S}^{-1} \mathrm{~K}^{-1}$ & -12998 \\
\hline$h_{4}$ & $S J^{-1}$ & 1508 \\
\hline$h_{5}$ & $\mathrm{~s} \mathrm{~kg}^{-1}$ & 77.766 \\
\hline$c_{0}$ & $\mathrm{~J} \mathrm{~S}^{-1} \mathrm{~K}^{-1}$ & 11.8 \\
\hline$c_{1}$ & $\mathrm{~J} \mathrm{~S}^{-1} \mathrm{~K}^{-1} \mathrm{~V}^{-1}$ & 2.755 \\
\hline$c_{2}$ & $\mathrm{~J} \mathrm{~s}^{-1} \mathrm{~K}^{-1} \mathrm{~V}^{-2}$ & -0.19 \\
\hline$k_{\mathrm{p}}$ & $\mathrm{J} \mathrm{S}^{-1} \mathrm{~K}^{-1}$ & 0.39 \\
\hline
\end{tabular}

Table 3

Values of water masses in the model identified from the step response.

\begin{tabular}{ccc}
\hline Parameter & Unit & Nominal value \\
\hline$M_{\mathrm{H}}$ & $\mathrm{kg}$ & 0.08 \\
$M_{\mathrm{P}}$ & $\mathrm{kg}$ & 0.22 \\
$M_{\mathrm{C}}$ & $\mathrm{kg}$ & 0.27 \\
\hline
\end{tabular}

\section{Table 4}

Identified values of process model delays deduced from the step response. The minimum value corresponds to $u_{\mathrm{p}}=6 \mathrm{~V}$, whereas the maximum one corresponds to $u_{\mathrm{P}}=2 \mathrm{~V}$.

\begin{tabular}{ccccc}
\hline Parameter & Unit & $\begin{array}{c}\text { Minimum } \\
\text { value }\end{array}$ & $\begin{array}{c}\text { Nominal } \\
\text { value }\end{array}$ & $\begin{array}{c}\text { Maximum } \\
\text { value }\end{array}$ \\
\hline$\tau_{\mathrm{H}}$ & $\mathrm{s}$ & 3 & 3 & 3 \\
$\tau_{\mathrm{HC}}$ & $\mathrm{S}$ & 114 & 118 & 132 \\
$\tau_{\mathrm{C}}$ & $\mathrm{S}$ & 22 & 23 & 26 \\
$\tau_{\mathrm{FC}}$ & $\mathrm{S}$ & 11 & 12 & 14 \\
$\tau_{\mathrm{CH}}$ & $\mathrm{S}$ & 6 & 7 & 9 \\
\hline
\end{tabular}


Table 5

Nominal parameter values of model (18) at the operating point (19) with $\vartheta_{a}=24^{\circ} \mathrm{C}$.

\begin{tabular}{cc}
\hline Parameter & Value \\
\hline$b_{0}$ & $-2.052 \times 10^{-7}$ \\
$b_{0 D}$ & $2.334 \times 10^{-6}$ \\
$a_{0}$ & $1.413 \times 10^{-4}$ \\
$a_{0 D}$ & $-7.625 \times 10^{-5}$ \\
$a_{1}$ & $8.989 \times 10^{-2}$ \\
$a_{2}$ & 0.1767 \\
$\tau_{0}(\mathrm{~s})$ & 1.5 \\
$\tau_{b}(\mathrm{~s})$ & 141 \\
$\tau_{a}(\mathrm{~s})$ & 151 \\
\hline
\end{tabular}

A comparison of measured and modeled step responses for $\Delta P_{\mathrm{H}}=150 \mathrm{~W}$ at the operating point (19) with $\vartheta_{a}=24^{\circ} \mathrm{C}$ is displayed in Fig. 5, which verifies and validates the model (11)-(15) and its identified parameter values.

\section{Results and discussion}

The algebraic control design approach along with robust stability and performance introduced in Section 2 were applied to the laboratory model with the HX the description, mathematical model and identification were outlined in Section 3. There are several motivations why to consider robustness issues to the controlled process.

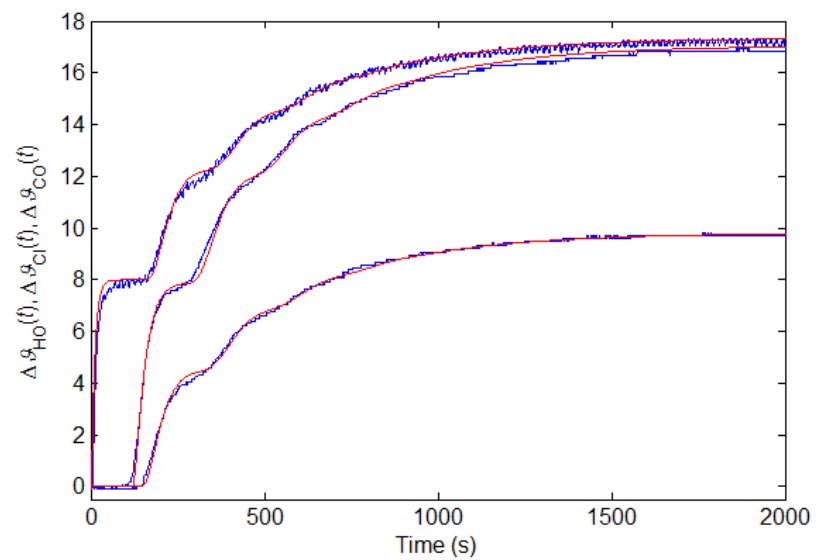

Fig. 5. Measured (blue) and modeled (red) step responses for the operating point (19) and $\vartheta_{a}=24^{\circ} \mathrm{C}$.
Namely, there are perturbations in model parameter values and properties due to many non-modeled internal and external influences, such as temperature-dependent heat transmission coefficients, specific heat capacities, pump characteristics, fluctuations in input power and voltage, etc. Ambient temperature stands for the most significant external factor; it has been measured that it varies within the range $\vartheta_{a} \in[18,28]^{\circ} \mathrm{C}$ during the year. Moreover, the introduced nominal parameters represent mean values calculated upon the measured static and dynamic responses. As mentioned above, it has been found that $k_{\mathrm{p}} \in[0.16,0.62] \mathrm{J} \mathrm{s}^{-1} \mathrm{~K}^{-1}$ during calculations from measured data. Other measured transmission coefficients vary according to particular input values as $k_{\mathrm{H}} \in[1.07,2.76] \quad \mathrm{J} \mathrm{s}^{-1} \mathrm{~K}^{-1} \quad$ with $u_{\mathrm{P}} \in[4,6] \mathrm{V}$ and $P_{\mathrm{H}} \in[225,400] \mathrm{W}$, and $k_{\mathrm{C}} \in[14.2,21.4] \quad \mathrm{J} \mathrm{s}^{-1} \mathrm{~K}^{-1}$ for $u_{\mathrm{C}} \in[1,6] \mathrm{V}$, and delay variations have been provided in Table 4. Last but not least, the temperature measurement error is influenced by the readability of $0.1^{\circ} \mathrm{C}$ for process outputs and that of $0.5{ }^{\circ} \mathrm{C}$ for $\vartheta_{a}$.

Thus, for robust control design in this paper, it is expected that there are perturbations in uncontrolled process inputs and (corresponding) parameters with respect to the operating point (19) as follows: $u_{\mathrm{P}} \in[4.5,5.5] \mathrm{V}$, $u_{\mathrm{C}} \in[2.5,3.5] \mathrm{V}$, which yields modeled delays $\tau_{\mathrm{HC}}=[116,120] \mathrm{s}, \quad \tau_{\mathrm{C}}=[22,24] \mathrm{s}, \quad \tau_{\mathrm{CH}}=[6.5,7.5] \mathrm{s}, \quad$ and consider variations $\vartheta_{a} \in[16,30]^{\circ} \mathrm{C}, k_{\mathrm{P}} \in[0.1,0.7] \mathrm{J} \mathrm{s}^{-1} \mathrm{~K}^{-1}$.

Function $W_{M}(s)$ is constructed in such a way that it constitutes a cover for functions $\left|G(s) / G_{0}(s)-1\right|$ for all perturbed $G(s)$ and all nonnegative frequencies $\omega$ under the substitution $s=\mathrm{j} \omega$, as required by (8). A possibility how to cope with this task is based on the factorization

$W_{M}(\mathrm{j} \omega)=\prod_{i=1}^{N} W_{M, i}(\mathrm{j} \omega)$

where $N$ depends on the shape of the covered plots, and factors have the following general form

$W_{M, i}(\mathrm{j} \omega)=k_{0, i}\left(1+\frac{\mathrm{j} \omega}{\omega_{C, i}}\right)^{(-1)^{k_{i}}}$

The value of $\omega_{C, i}$ means the particular cutoff frequency; then, $\left|W_{M, i}(\mathrm{j} \omega)\right|$ (in $\mathrm{dB}$ ) can be approximated by a constant function for the range $\omega \in\left[0, \omega_{C, i}\right]$ whereas it behaves as a linear ascending/descending function with the slope of $(-1)^{k_{i}} 20 \mathrm{~dB}, \quad k_{i} \in\{-1,1\}$, per the decade for $\omega \in\left[\omega_{C, i}, \infty\right]$. Note that for a constant $W_{M, i}$, it is set $\omega_{C, i} \rightarrow \infty$ for an appropriate $k_{0, i}$. The eventual shape of $\left|W_{M, i}(\mathrm{j} \omega)\right|$ is then simply given by the superposition of all the factors. Hence, one has to determine suitable $\omega_{C, i}$ and then to select 
particular functions $\left|W_{M, i}(\mathrm{j} \omega)\right|$, the superposition of which results in the desired shape.

In our study case, we can determine $\omega_{C, \cdot}=\{0.018,0.067,0.125,0.8, \infty\}$, and $k_{0, \cdot}=1$ for all $\omega_{C, i}$ except for the infinity where $k_{0,5}=0.12$ is set. The eventual $W_{M}(s)$ reads

$W_{M}(s)=0.12 \frac{(55 s+1)(8 s+1)}{(15 s+1)(1.25 s+1)}$

and the corresponding Bode plots are displayed in Fig. 6, from which low conservatism can be identified.

Let us now concisely introduce the controller structure derivation. In the accordance to (2), the controlled process modeled as (18) has its numerator and denominator factorizations as $B(s)=b(s) / \lambda(s), \quad A(s)=a(s) / \lambda(s)$, respectively, with $\lambda(s)=\left(s+\lambda_{0}\right)^{3}, \lambda_{0}>0$.

It is useful to consider a linearwise reference signal, i.e. $F_{R}(s)=s^{2}$, and let the disturbance be modeled as a stepwise function, $F_{D}(s)=s$. These options are motivated by practical reasons. It is more comfortable for a user to ask for a gradual growth/decline in the reference temperature than to be faced with an abrupt change in the reference. This function is, for instance, included in most of the modern programmable thermostats. In the contrary, precipitous influences affecting the manipulated input prevail and it is usually sufficient not to consider a more complex function in the model. For instance, the measurement on the laboratory appliance can be harmed by a sudden window opening or a fast human movement in the room. The effect of a harmonic electrical disturbance can be neglected since it is marginal in amplitude and fast compared to system dynamics.

After some calculations on (3) and (4) it can be observed that condition (6) can not be satisfied since $V(s)$ does not have a sufficient number of degrees of freedom. Therefore, the extension $\bar{V}(s)=V(s)\left(s+\lambda_{1}\right) /\left(s+\lambda_{1}\right), \lambda_{1}>0$ is to be made to perform (7). Then $q_{N}(s)=(1-\gamma) \lambda_{1} s^{2}$; hence, there are three tunable parameters to be appropriately set in delayed controller structures, $\lambda_{0}, \lambda_{1}, \gamma$, with regard to robustness conditions.

It can be shown by further computations that robust stability condition (9) does not depend on $\lambda_{1}, \gamma$ and it is satisfied for $0<\lambda_{0} \leq 0.055$. By considering the selected ranges $\quad 0.2 \leq \gamma \leq 0.8, \quad 0.001 \leq \lambda_{1} \leq 0.009 \quad$ (in the accordance to plant and external signals dynamics), the following sensitivity weight function $W_{P}(s)$ for the nominal $S_{0}(s)$ can be determined

$W_{P}(s)=0.11 \cdot 10^{-5} \frac{(1000 s+1)(90 s+1)(10 s+1)}{s^{2}(1.5 s+1)}$

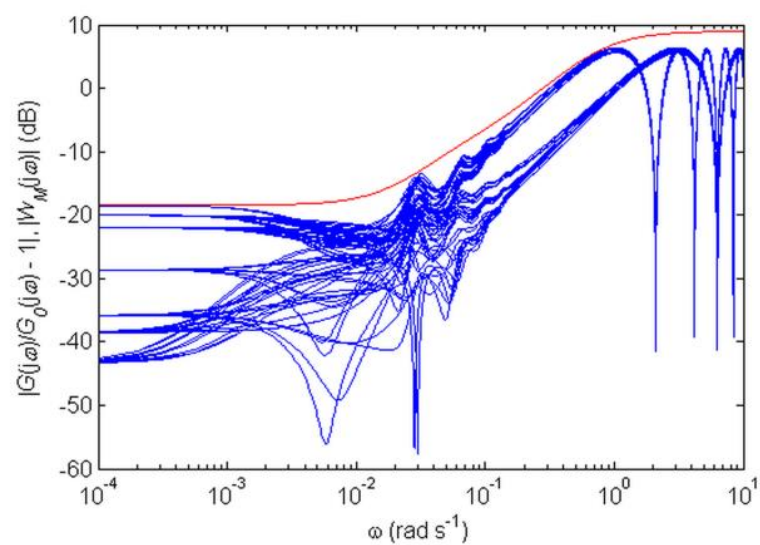

Fig. 6. Bode plots of $G(s) / G_{0}(s)-1$ (blue) and $W_{M}(s)$ (red) given by (22).

Function (23) must cover the plot $\left|1 / S_{0}(\mathrm{j} \omega)\right|, \forall \omega \geq 0$, with a sufficient gain margin, and it is constructed in the accordance and analogously to the idea introduced for $W_{M}(s)$ above. Note that the factor $W_{P, i}(s)=1 / s$ is obtained by the setting $\omega_{C, i} \rightarrow 0, k_{0, i}=k_{i}=1$ in (21).

The eventual acceptable parameter ranges set can be then obtained by the application of condition (10) with (22) and (23). Let us now face these results with another idea how to set the triplet $\lambda_{0}, \lambda_{1}, \gamma$ conveniently.

Assume the following control response performance (quality) measures: The relative overshoots of $y(t)$ after a step change and a linear-to-constant transition of $r(t)$, respectively, denoted as $\Delta e_{1, \max }$ and $\Delta e_{2 \text {,max }}$; the relative overshoot after a step change of $d(t)$ denoted as $\Delta e_{d, \max }$; integral absolute errors (IAEs) of the output responses caused by reference deviations as introduced above, denoted by $e_{1, \mathrm{AE}}, e_{2, \mathrm{AE}}, e_{d, \mathrm{AE}}$, respectively; the overall IAE of $e(t)$ denoted as $e_{\mathrm{IAE}}$; and the overall manipulated input energy formulated in terms of the IAE of $u(t)$ denoted as $u_{\text {IAE }}$. The goal is to minimize these values with respect to values of $\lambda_{0}, \lambda_{1}, \gamma$ in the specified ranges. To avoid excessive computations, consider the mean values $\bar{\lambda}_{0}=0.028, \bar{\lambda}_{1}=0.005, \bar{\gamma}=0.5$ and compute the corresponding dimensionless sensitivities of measures above to the controller coefficients as

$\sigma_{f, x}=\frac{\Delta f(x) / f(x)}{\Delta x / x}$

where $f$ means a particular performance measure, $x$ stands for a selectable coefficient and $\Delta$ expresses the value deviation. Values of (24) obtained by simulations in the Matlab ${ }^{\circledR} /$ Simulink $^{\circledR}$ environment are summarized in Table 6, from which it is apparent that suitable parameter values within the selected ranges can not be simply found. 
Table 6

Dimensionless sensitivities of control performance measures to controller parameter variations according to (24) in mean values of possible parameter ranges $\bar{\lambda}_{0}=0.028, \bar{\lambda}_{1}=0.005, \bar{\gamma}=0.5$.

\begin{tabular}{|c|c|c|c|c|c|c|c|c|}
\hline Parameter & $\sigma_{\Delta e_{1, \text { max }},}$ & $\sigma_{\Delta e_{2, \text { max }}}$ & $\sigma_{\Delta e_{d, \max },}$ & $\sigma_{\mathrm{e}_{\mathrm{l}, \mathrm{AE}},}$ & $\sigma_{e_{2, \mathrm{AE}}}$ & $\sigma_{e_{d, \mathrm{AE}}}$ & $\sigma_{e_{\mathrm{AE}}}$ & $\sigma_{u_{\mathrm{AE}},}$ \\
\hline$\lambda_{0}$ & $9.74 \times 10^{-2}$ & $-1.68 \times 10^{-2}$ & $-4.82 \times 10^{-2}$ & -0.179 & -0.321 & -0.263 & -0.218 & $1.01 \times 10^{-2}$ \\
\hline$\lambda_{1}$ & 0.269 & $-4.55 \times 10^{-4}$ & $1.95 \times 10^{-2}$ & $1.22 \times 10^{-2}$ & -0.114 & $-1.01 \times 10^{-2}$ & $-5.87 \times 10^{-2}$ & $4.14 \times 10^{-4}$ \\
\hline$\gamma$ & 0.718 & $-1.27 \times 10^{-2}$ & $5.19 \times 10^{-2}$ & $-9.47 \times 10^{-2}$ & -0.428 & $-3.01 \times 10^{-2}$ & -0.262 & $3.31 \times 10^{-3}$ \\
\hline
\end{tabular}

To solve this task, let us use the following formula

$x_{\mathrm{opt}}=\bar{x}-0.5[x] \frac{\sum_{i=1}^{8} l_{i} \sigma .}{\sum_{i=1}^{8} l_{i} \mid \sigma .}$

where $x_{\text {opt }}$ is the eventual (optimal) parameter value, $\bar{x}$ stands for the mean value within the considered interval of the length $[x]$, and $l_{i}$ is the weight coefficient. In the authors' opinion, from the practical point of view, the overall consumed energy and absolute deviations from desired temperatures are slightly more decisive than the integral measures of the control error; hence, let $l_{i}=2$ for $\Delta e_{\text {, } \max }$ and $u_{\mathrm{IAE}}$, and $l_{i}=1$ for the other measures. Then the final parameters read $\lambda_{0, \mathrm{opt}}=0.0455, \lambda_{1, \mathrm{opt}}=0.0016$, $\gamma_{\text {opt }}=0.248$ and it can be checked that robustness conditions (9) and (10) are satisfied for this setting.

The comparison of eventual simulated and measured control and controlled signals as deviations from the operating point (19) are displayed in Fig. 7 and Fig. 8, respectively. The designed controllers clearly yield stable control process with the asymptotical reference tracking and the stepwise load disturbance rejection. A rather considerable disproportion between simulated and measured steady-state values of $u_{0}(t)=\Delta P_{\mathrm{H}}(t)$ might be given by modeling errors of static gains or lower ambient temperature when measurements $\left(\vartheta_{a} \approx 22^{\circ} \mathrm{C}\right)$.

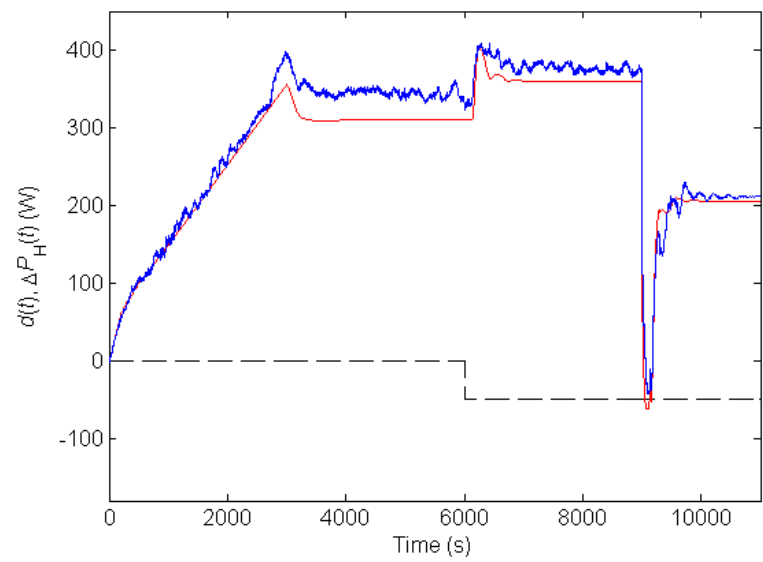

Fig. 7. Measured (blue line) and modeled (red line) control actions (manipulated input) $u_{0}(t)=\Delta P_{\mathrm{H}}(t)$ in the vicinity of the operating point (19). The dashed line indicates the injected load disturbance $d(t)=-50 \cdot 1(t-6000) \mathrm{W}$.

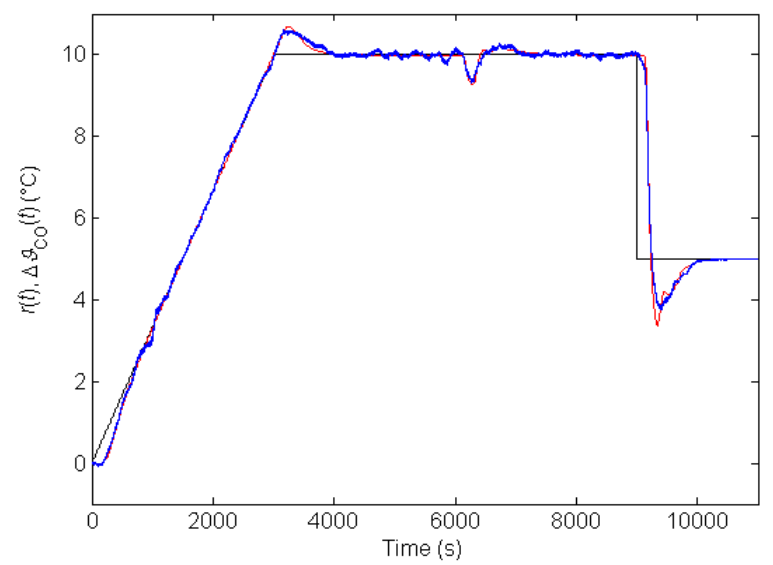

Fig. 8. Measured (blue line) and modeled (red line) control responses $y(t)=\Delta \vartheta_{\mathrm{CO}}(t)$ in the vicinity of the operating point (19). The solid black line indicates the reference signal $r(t)$.

As up to $90 \%$ of control feedback loops in practice are equipped with PID controllers or some of their generalizations, it is desirable to approximate infinitedimensional (anisochronic, delayed) controllers by standardized finite-dimensional ones. It is natural and inherent that any kind of such an approximation yields a loss of information about the system spectrum because of a reduction of an infinite spectrum to a finite one. Since $G_{C}(s)$ behaves asymptotically like a PID with double integrator and $G_{Q}(s)$ like a proportional term, let us choose the following approximating structures

$$
\hat{G}_{C}(s)=\frac{c_{2} s^{2}+c_{1} s+c_{0}}{s^{2}}, \hat{G}_{Q}(s)=q_{0}
$$

with real-valued polynomial coefficients.

In the literature, engineeringly applicable approximation methods of exponential elements were well summarized in [42] but there has been a lack of methods dealing with approximation of whole quasipolynomial fractions. The authors studied various frequency-based methods to solve this task for delayed controller [43], where promising results have been observed with the use of the Padé approximation. Similar findings about this idea have been recently obtained while a polynomial approximation of quasipolynomials, when searching of the stability margin for TDSs [44]. Hence, we decided to adopt the general idea of the Padé approximation to (26) which can be expresses by the rule 


$$
\begin{aligned}
& {\left[\frac{\mathrm{d}^{i}}{\mathrm{~d} s^{i}} G_{C}^{-1}(s)\right]_{s=0}=\left[\frac{\mathrm{d}^{i}}{\mathrm{~d} s^{i}} \hat{G}_{C}^{-1}(s)\right]_{s=0}, i=1,2,3} \\
& G_{Q}(0)=\hat{G}_{Q}(0)
\end{aligned}
$$

These conditions then determine particular parameter values in (26) where the former condition agrees with the identity of Mclaurin series expansions of $G_{C}^{-1}(s)$ and $\hat{G}_{C}^{-1}(s)$. It is worth noting that non-inversed transfer functions can not be used here as they include zero pole. Moreover, the identity of zero derivatives does not include any undetermined variable to be calculated. The latter expression in (27) simply ensures that both the controllers have the same static gain (i.e. the proportional term).

However, it must be critically stated that the problem of a suitable approximation of an infinite-dimensional controllers by PID ones requires a separate future in-depth study, which is not the intention of this contribution.

The control responses of the process with controllers (26) obtained via (27) and the corresponding control inputs are shown in Figs. 9-10.

It can be stated again that ambient temperature higher than the nominal one during measurements has caused the difference in modeled and measured control actions; however, controlled outputs coincide very well. The use of approximating controllers has resulted in more oscillating inputs and outputs, and higher overshoots with more aggressive manipulated input compared to the original anisochronic controllers. However, the overall performance displayed in Fig. 10 is still acceptable from the practical point of view except for the significant control error peak after the step-down change in the reference value at $t=9000 \mathrm{~s}$. The disadvantage of the use of the original controllers is in a more complex implementation effort because of controllers' dynamics combining integral and delayed terms.

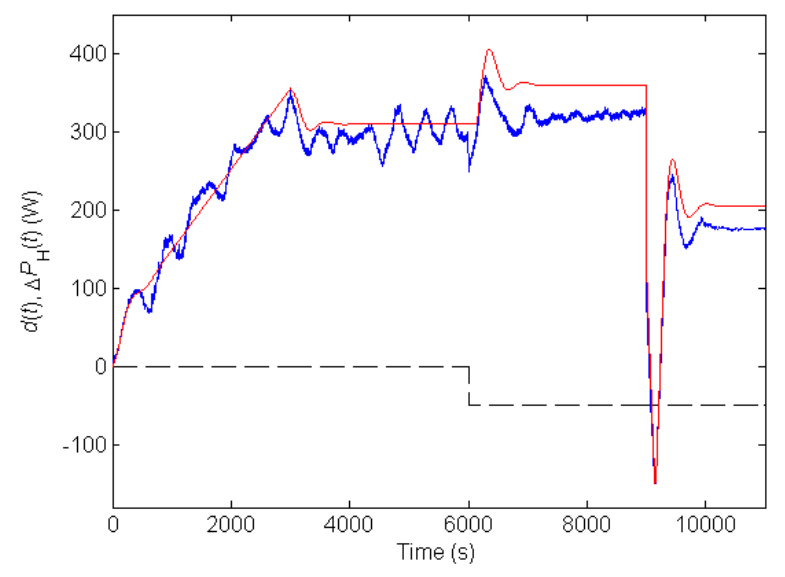

Fig. 9. Measured (blue line) and modeled (red line) control actions (manipulated input) $u_{0}(t)=\Delta P_{\mathrm{H}}(t)$ in the vicinity of the operating point (19) when using approximating controllers (26). The dashed line indicates the injected load disturbance $d(t)=-50 \cdot 1(t-6000)$ W.

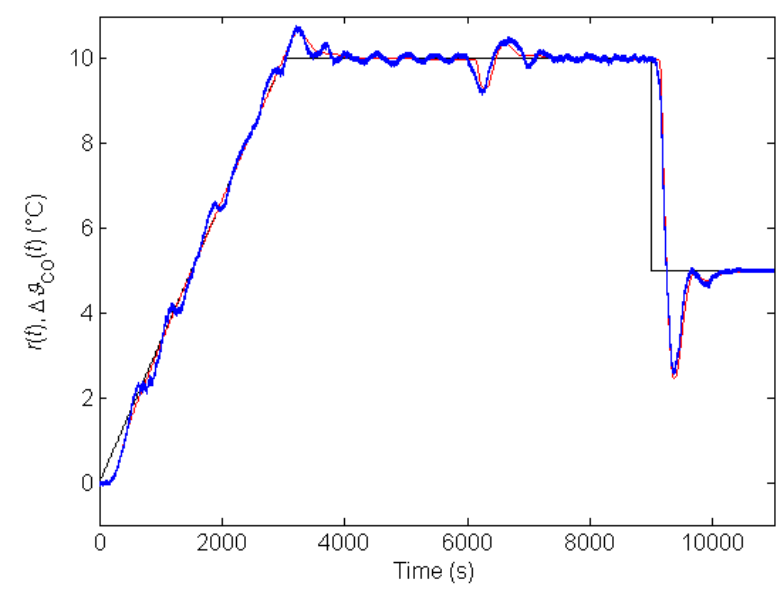

Fig. 10. Measured (blue line) and modeled (red line) control responses $y(t)=\Delta \vartheta_{\mathrm{CO}}(t)$ in the vicinity of the operating point (19) when using approximating controllers (26). The solid black line indicates the reference signal $r(t)$.

\section{Conclusions}

An alternative algebraic control approach for heating networked processes with heat exchangers evincing long internal delays is presented in this paper. It is implemented on control of a laboratory circuit heating system. The main contribution of this paper involves three leading aspects. First, the presented algebraic methodology using a special ring of quasipolynomial meromorphic functions is based on the process model without any attempt to approximate delays or model order, which enables to include the complete model dynamics information. Second, the branched control system structure with two feedback controllers allows the user to partially decouple the reference tracking from disturbance rejection. Third, robust stability and performance principles are applied to the designed controllers' structures, which yields the eventual controller parameters' values, along with the minimization of a multicriterial function comprising control error peaks and integral criteria of energy consumption. The presented results proof a very good performance and applicability of the proposed method. The disadvantage of the presented algebraic approach can primarily be seen in its dependence on the process model accuracy and in a possible complexity of the controller dynamics. Another contribution is that a possible finite-dimensional approximation of original controllers is proposed and verified; however, it suffers from worse a control response performance. The future research will be focused on a more sophisticated controller structures derivation and their optimal parameters determination, and on the extension of the presented approach to multi-input multioutput processes.

\section{Acknowledgements}

This work was supported by the European Regional Development Fund under the project CEBIA-Tech Instrumentation No. CZ.1.05/2.1.00/19.0376. 


\section{Nomenclature}

Symbols

C set of complex-valued numbers

C specific heat capacity of water $\left(\mathrm{J} \mathrm{kg}^{-1} \mathrm{~K}^{-1}\right)$

$c_{C u} \quad$ specific heat capacity of copper $\left(\mathrm{J} \mathrm{kg}^{-1} \mathrm{~K}^{-1}\right)$

$d(t) \quad$ load disturbance

$e(t) \quad$ control error

$G(s) \quad$ controlled plant transfer function

$G_{c}(s)$ inner-feedback controller

$G_{Q}(s)$ outer-feedback controller

$\overline{\mathbf{G}}(s) \quad$ transfer function matrix

$H_{\infty} \quad$ Hardy space of holomorphic functions with bounded gain in the right-half complex plane

$k \quad$ heat transmission coefficient $\left(\mathrm{J} \mathrm{s}^{-1} \mathrm{~K}^{-1}\right)$

l weight coefficient

$\dot{m}(t) \quad$ water mass flow rate $\left(\mathrm{kg} \mathrm{s}^{-1}\right)$

$M \quad$ water masses $(\mathrm{kg})$

$P_{\mathrm{H}}(t) \quad$ input power to the heater (W)

$r(t) \quad$ reference signal

$r_{Q}[s] \quad$ set of quasipolynomials

$R_{Q M} \quad$ ring of special quasipolynomial meromorphic functions

$R^{2} \quad$ coefficient of determination

$\mathrm{R} \quad$ set of real-valued numbers or vectors

$s \quad$ Laplace transform variable

$S_{0}(s)$ nominal sensitivity function

$S(s) \quad$ perturbed sensitivity function

$t$ time $(\mathrm{s})$

$T_{0}(s)$ nominal complementary sensitivity function

$u(t)$ manipulated input affected by the load disturbance

$u_{\mathrm{C}}(t) \quad$ voltage input to the heat exchanger fan (V)

$u_{\mathrm{p}}(t) \quad$ voltage input to the pump (V)

$u_{0}(t)$ manipulated input

$W_{M}(s)$ uncertainty frequency distribution weight function

$W_{P}(s)$ frequency distribution sensitivity weight function

$y(t) \quad$ system output

$\varnothing \quad$ empty set

\section{Greek letters}

$\gamma \quad$ weight controller parameter

$\Delta t \quad$ sampling period

$\Delta(s)$ bounded stable variable function

$\vartheta_{\mathrm{a}} \quad$ constant ambient temperature $\left({ }^{\circ} \mathrm{C}\right)$

$\vartheta_{\mathrm{CI}}(t)$ inlet stream temperature to the heat exchanger $\left({ }^{\circ} \mathrm{C}\right)$

$\vartheta_{\mathrm{CO}}(t)$ outlet stream temperature from the heat exchanger $\left({ }^{\circ} \mathrm{C}\right)$

$\vartheta_{\mathrm{HO}}(t) \quad$ outlet stream temperature from the heater $\left({ }^{\circ} \mathrm{C}\right)$

$$
\begin{array}{ll}
\lambda_{0}, \lambda_{1} & \text { controller parameters } \\
\sigma & \text { sensitivity function } \\
\tau & \text { particular delay value (s) } \\
\mathbf{T} & \text { time-delay vector (s) }
\end{array}
$$

\section{Subscripts}

a ambient

C cooler (heat exchanger)

$\mathrm{F} \quad$ fan

$\mathrm{H}$ heater

O output

$P \quad$ piping

0 nominal system

$+\quad$ subset in the right-half plane

\section{Superscripts}

s steady state

\section{Abbreviations}

ANN artificial neural network

BIBO bounded-input bounded-output

$\mathrm{HX}$ heat exchanger

IAE integral absolute error

LTI linear time-invariant

MPC model predictive control

PID proportional-integral-derivative

PLC programmable logic controller

RMPC robust model predictive control

TDS time delay system

TFC two-feedback-controllers

TTL transistor-transistor logic

\section{References}

[1] R. Sipahi, T. Vyhlídal, S.-I. Niculescu, P. Pepe (eds.), Time Delay Systems: Methods, Applications and New Trends, Springer, New York, 2012.

[2] W. Michiels, S.-I. Niculescu, Stability, Control and Computation of Time-Delay Systems, SIAM Publications, Philadelphia, 2014.

[3] T. Vyhlídal, J.-F. Lafay, R. Sipahi (eds.), Delay Systems: From Theory to Numerics and Applications, Springer, New York, 2014.

[4] W. Michiels, S.-I. Niculescu, Stability and Stabilization of Time-Delay Systems. An Eigenvalue Based Approach, SIAM Publications, Philadelphia, 2007

[5] J.J. Loiseau, W. Michiels, S.-I. Niculescu, R. Sipahi (eds.), Topics in Time Delay Systems: Analysis, Algorithm and Control, Springer, Berlin, 2009

[6] S. Gumussoy, Coprime-inner/outer factorization of SISO time-delay systems and FIR structure of their optimal H-infinity controllers, Int. J. Robust Nonlin. Control 22 (2012) 981-998, http://dx.doi.org/10.1002/rnc.1740.

[7] M. Vidyasagar, Control System Synthesis: A Factorization Approach, MIT Press, Cambridge, M. A., 1985.

[8] C. Foias, H. Özbay, A. Tannenbaum, Robust Control of Infinite Dimensional Systems: Frequency Domain Methods, Springer, Berlin 1996.

[9] P. Zítek, V. Kučera, Algebraic design of anisochronic controllers for time delay systems, Int. J. Control 76 (2003) 1654-1665.

[10] L. Pekař, A ring for description and control of time-delay systems, WSEAS Trans. Syst. 11 (2012) 571-585. 
[11] R.F. Curtain, K. Morris, Transfer functions of distributed parameters systems, Automatica 45 (2009) 1101-1116, http://dx.doi.org/10.1016/j.automatica.2009.01.008.

[12] R.W. Serth, T.G. Lestina, 3 - Heat Exchangers, Process Heat Transfer, in: Principles, Applications and Rules of Thumb, 2014, pp. 67-100, http://dx.doi.org/10.1016/B978-0-12-397195-1.00003-0.

[13] S. Sanaye, H. Hajabdollahi, Multi-objective optimization of shell and tube heat exchangers, Appl. Therm. Eng. 30 (14-15) (2010) 19371945, http://dx.doi.org/10.1016/..applthermaleng.2010.04.018.

[14] P.S. Varbanov, J.J. Klemeš, F. Friedler, Cell-based dynamic heat exchanger models - direct determination of the cell number and size, Comput. Chem. Eng. 35 (2011) 943-948, http://dx.doi.org/10.1016/i.compchemeng.2011.01.033.

[15] S. Wang, D.C. Gao, Y. Sun, F. Xiao, An online adaptive optimal control strategy for complex building chilled water systems involving intermediate heat exchangers, Appl. Therm. Eng. 50 (2013) 614-628, http://dx.doi.org/10.1016/j.applthermaleng.2012.06.010.

[16] M. Keshavarz, M.B. Yazdi, M.R. Jahed-Motlagh, Piecewise affine modeling and control of a boilereturbine unit, Appl. Therm. Eng. 30 (2010) http://dx.doi.org/10.1016/j.applthermaleng.2009.11.009.

[17] J. Alvarez-Ramirez, I. Cervantes, R. Femat, Robust controllers for a heat exchanger. Ind. Eng. Chem. Res. 36 (1997) 382-388, http://dx.doi.org/10.1021/ie960496m.

[18] A. Maidi, M. Diaf, J.-P. Corriou, Boundary geometric control of a counter-current heat exchanger, J. Process Contr. 19 (2009) 297-313.

[19] M. Bakošová, J. Oravec, Robust model predictive control for heat exchanger network, Appl. Therm. Eng. 73 (2014) 924-930, http://dx.doi.org/10.1016/j.applthermaleng.2014.08.023.

[20] A. Michel, A. Kugi, Model based control of compact heat exchangers independent of the heat transfer behavior, J. Process Contr. 24 (2014) 286-298, http://dx.doi.org/10.1016/i.jprocont.2014.02.003.

[21] G.C. Díaz, Simulation and Control of Heat Exchangers Using Artificial Neural Networks, doctoral thesis, Graduate School of Notre Dame, Notre Dame, Indiana, 2000.

[22] A. Vasičkaninová, M. Bakošová, A. Mészáros, J.J. Klemeš, Neural network predictive control of a heat exchanger, Appl. Therm. Eng. 31 (2011) http://dx.doi.org/10.1016/i.applthermaleng.2011.01.026.

[23] A. Vasičkaninová, M. Bakošová, Control of a heat exchanger using neural network predictive controller combined with auxiliary fuzzy controller, Appl. Therm. Eng. 89 (2015) 1046-1053, http://dx.doi.org/10.1016/..applthermaleng.2015.02.063.

[24] F. Peng, G. Cui, Efficient simultaneous synthesis for heat exchanger network with simulated annealing algorithm, Appl. Therm. Eng. 78 (2015)

136-149, http://dx.doi.org/10.1016/j.applthermaleng.2014.12.03.

[25] P. Zítek, J. Hlava, Anisochronic internal model control of time-delay systems, Control Eng. Pract. 9 (2001) 501-516, http://dx.doi.org/10.1016/S0967-0661(01)00013-2.

[26] N. Saman, H. Mahdi, Analysis of the delay hot/cold water problem, Energy 21 (1996) 395-400.

[27] K. Paulů, Multi-Parameter Heating Plant Control by Means of Feedback States, master thesis, Faculty of Mechanical Engineering, Czech Technical University in Prague, Prague, 2006 (in Czech).

[28] M. Bakošová, J. Oravec, Robust model predictive control of heat exchangers, Chem Eng. Trans. 73 (2012) 1465-1470, http://dx.doi.org/10.3303/CET1229245.

[29] J.Q. Huang, F.L. Lewis, Neural-network predictive control for nonlinear dynamic systems with time-delay, IEEE Trans. Neural Networ. 14 (2003) 377-389.

[30] J. Oravec, M. Bakošová, A. Mészáros, N. Míková, Experimental investigation of alternative robust model predictive control of a heat exchanger, Appl. Therm. Eng. (2016), in press, http://dx.doi.org/10.1016/j.applthermaleng.2016.05.046.

[31] T.A. Horst, H.-S. Rottengruber, M. Seifert, J. Ringler, Dynamic heat exchanger model for performance prediction and control system design of automotive waste heat recovery systems, Appl. Energ. 105 (2013) 293-303, http://dx.doi.org/10.1016/i.apenergy.2012.12.060.

[32] S. Talaš, V. Bobál, Measurable error compensation with GPC in a heat-exchanger with a traffic delay, in: Nostradamus 2014: Prediction, Modeling and Analysis of Complex Systems, Springer, Berlin, 2014 pp. 281-290.

[33] R. Holiš, V. Bobál, Possible approaches of disturbance compensation of time-delayed systems using predictive control, in: Proc. 29th Europ. Conf. Model. Simul. (ECMS 2015), Varna, Bulgaria, 2015, pp. 305 311, http://dx.doi.org/10.7148/2015-0305.

[34] V. Bobál, P. Dostál, M. Kubalčík, S. Talaš, LQ control of heat exchanger - design and simulation, in: Proc. 29th Europ. Conf Model. Simul. (ECMS 2015), Varna, Bulgaria, 2015, pp. 239-245, http://dx.doi.org/10.7148/2015-0239.

[35] L. Pekař, R. Prokop, P. Dostálek, Circuit heating plant model with internal delays, WSEAS Trans. Syst. 8 (2009) 1093-1104.

[36] M. Green, D.J.N. Limebeer, Linear Robust Control, Dover Publications, New York, 2012.

[37] R. Matušů, Robust stabilization of interval plants by means of two feedback controllers, Int J Circ Syst Signal Pr 9 (2015) 427-434.

[38] M. Hofreiter, P. Trnka, M. Hunčovský, P. Siegel, Extended relay feedback identification and anisochronic control, Int $\mathrm{J}$ Control Syst Robot 1 (2016) 57-62.

[39] A. O'Dwyer, Handbook of PI and PID Controller Tuning Rules, Imperial College Press, London, 2009.

[40] J.R. Partington, C. Bonnet, $\mathrm{H} \infty$ and BIBO stabilization of delay systems of neutral type, Syst. Control Lett. 52 (2004) 283-288 (2004), http://dx.doi.org/10.1016/i.sysconle.2003.09.014.

[41] Regmet, Surface Contact Temperature Sensor, 2016 $<$ regmet.cz/EN/download/datasheets/P14U I en.pdf> (accessed November 14, 2016).

[42] J.R. Partington, Some frequency-domain approaches to the mode reduction of delay systems. Annu. Rev. Control 28 (2004), 65-73, http://dx.doi.org/10.1016/i.arcontrol.2004.01.007

[43] L. Pekař, E. Kurečková, R. Prokop, On finite-dimensional transformations of anisochronic controllers designed by algebraic means: A user interface, in: MATLAB - A Fundamental Tool fo Scientific Computing and Engineering Applications - Volume 2, InTech, Rijeka, Croatia, 2012, pp. 91-118, http://dx.doi.org/10.5772/46472.

[44] L. Pekař, R. Prokop, On delay (in)dependent stability for TDS, in Ultra Modern Telecommunications and Control Systems and Workshops (ICUMT), 2015 7th International Congress on, IEEE, Brno, Czech Republic, 2015, pp. 73-78, http://dx.doi.org/10.1109/ICUMT.2015.7382408. 